\title{
Pyknodysostosis with Hearing Impairment
}

\author{
MOHD ASHRAF, ${ }^{1}$ ARSHAD FAROOQ, ${ }^{2}$ TANVEERI DAR, ${ }^{3} \mathrm{KHURSHEED} \mathrm{A} \mathrm{WANI}^{4}$
}

\begin{abstract}
Pyknodysostosis is a rare seclerosing bone disease that has autosomal recessive trait. It is characterized by small stature, diffuse osteosclerosis with tendency to transverse fractures, acro-osteolysis of fingers, with flattened and grooved nails. Other features include persistence of fontanelles, delayed closure of sutures, wormian bones, absence of frontal sinuses and obtuse mandibular gonial angle with relative mandibular prognathism. We report a 9-yearold girl having features of pyknodysostosis with progressive hearing impairment, in the form of otosclerosis.

Keyword: Craniofacial abnormalities, Hearing impairment, Otosclerosis, Pyknodysostosis, Seclerosing bone diseases.
\end{abstract}

\section{Introduction}

Pyknodysostosis, first described in 1962 by Maroteaux and Lamy, is a rare autosomal recessive disorder characterized by post natal onset of short limbed short stature and generalized hyperostosis. ${ }^{1}$ These patients have acroosteolysis with sclerosis of the terminal phalanges, a feature that is considered essentially pathognomonic. ${ }^{2}$ Other features include diffuse osteosclerosis with tendency to transverse fractures, flattened and grooved nails, wrinkled skin, kyphosis and scoliosis, persistence of fontanelles, delayed closure of sutures, presence of wormian bones, absence of frontal sinuses and obtuse mandibular gonial angle with relative mandibular prognathism are common features. ${ }^{3,4}$ The intellectual and sexual development is usually normal in these patients. In some patients a history of repeated chest infection and sleep apnea due to upper respiratory obstruction has been reported. ${ }^{5}$ Fronto-parietal bossing, thick calvaria, open fontanelles and sutures, hypoplastic paranasal sinuses, relative proptosis, beaked nose, blue sclera and hypoplastic midface are among cranial and maxillofacial features of this disorder. A greater tendency for fractures, especially of the long bone is a common finding in this disorder. ${ }^{6}$ However, hearing impairment with pyknodysostosis has not been presented as an association which is the illustrative interest in our case.

\section{Case Report}

A nine-year-old female presented with progressive impairment of hearing and short stature. Detailed history revealed that this patient was a product of consanguineous marriage and had uneventful antenatal, post natal period or other illness (meningitis) that could have association with this hearing impairment. There was no positive familial or drug history. This patient had normal neuromotor and sociobehavioral development with progressive haring impairment from last 6 months. Patient anthropometry showed

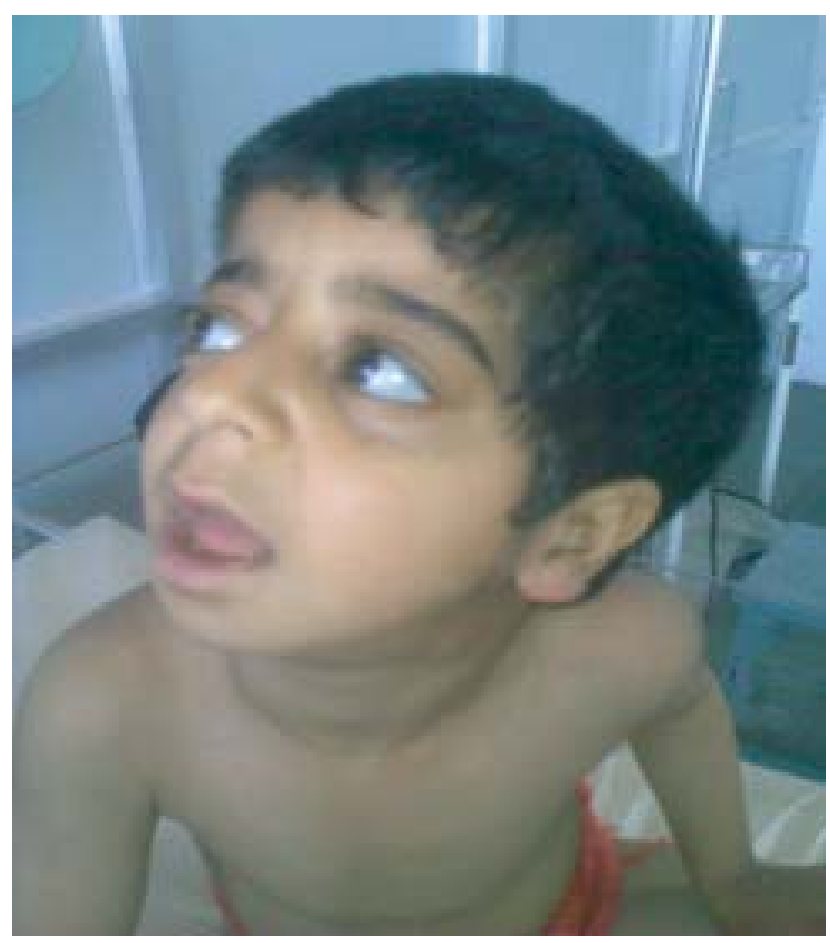

Fig.-1: Showing blue sclera, and beaked nose

1. Registrar, SKIMS Medical College, India

2. Associate Professor, SKIMS Medical College, India

3. Registrar, SKIMS Soura Srinagar, India

4. Consultant, GMC Srinagar, India

Correspondence: Dr Mohd Ashraf, Registrar, Department of Pediatrics, SKIMS Medical College, Bemina Srinagar. Email: aashraf_05@yahoo.co.in 
height of $110 \mathrm{~cm}(>120 \mathrm{~cm})$, arm span of $90 \mathrm{cms}$, weight of 19 $\mathrm{Kg}(<22.5 \mathrm{Kg})$, chest circumference of $57 \mathrm{~cm}$ with expansion of 2-3 cm on inspiration, head circumference of $53 \mathrm{~cm}$. She had dystrophic nails, persistent anterior fontenella, open skull sutures, blue sclera and sharp beaked nose (Fig 1,2,3), with normal USG cranium, cardiorespiratory status.

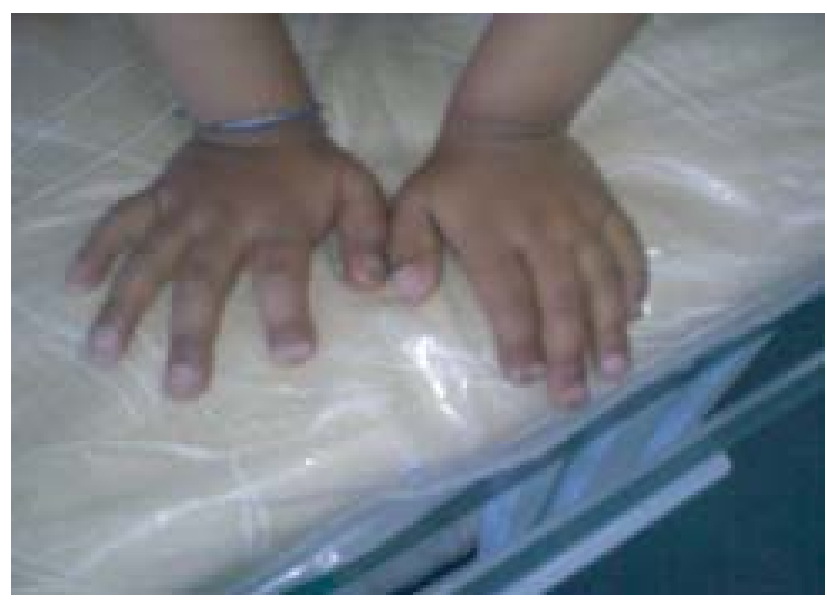

Fig.-2: Showing flat and grooved nails.

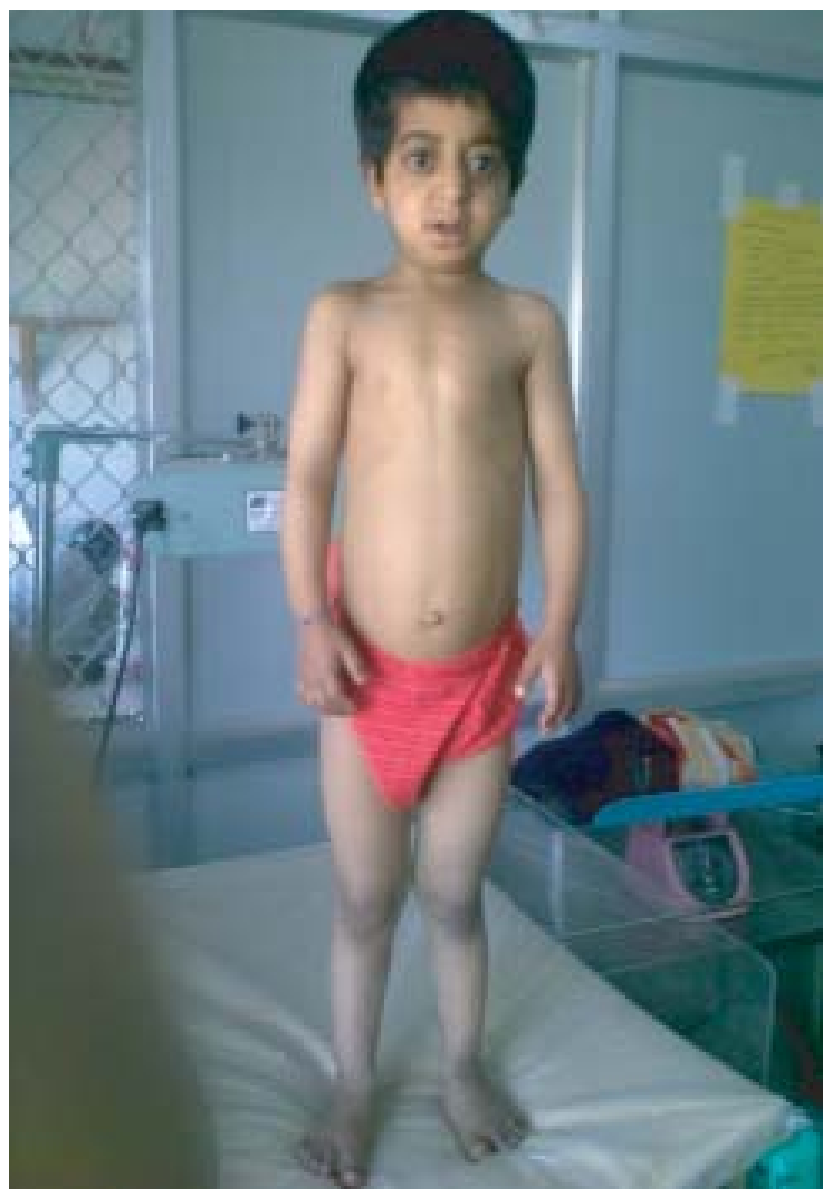

Fig.-3: General phenotypic appearance of pyknodysostotic patient
Laboratory tests showed $\mathrm{Hb} 10.8 \mathrm{~g} / \mathrm{dL}$, TLC $8.8 \times 10^{9}$, Polys 53, Lymphos 43\% and mixed 4\%. Platelet count was 2.8 lac/ $\mu \mathrm{L}$, S. $\mathrm{Ca}^{+2}$ 9.8/dL, S. Creatinine $0.6 \mathrm{mg} / \mathrm{dL}$, Alkaline phosphatase $200 \mathrm{IU} / \mathrm{L}$. However, there was generalized increase in bone density on limb X-rays, hypoplastic distal phalanges, and open skull sutures as shown in the (Fig 4) and pure tone audiometry and impedance audiometry showed features suggestive of bilateral otosclerosis with 52 decibel hearing loss.

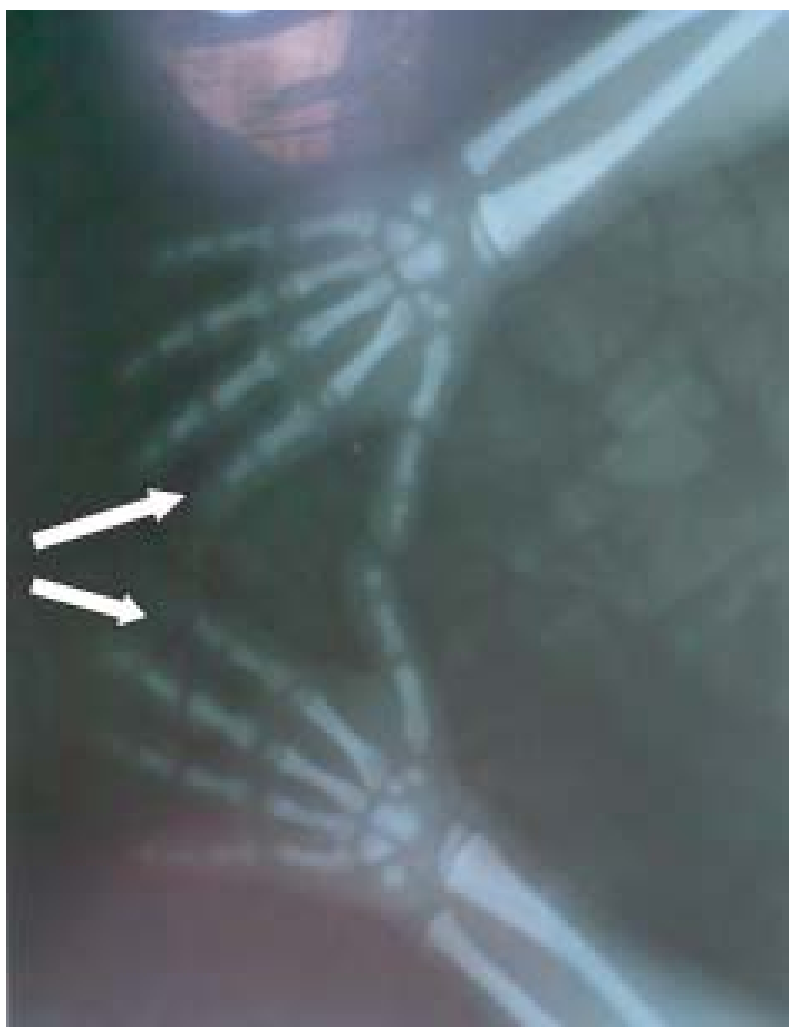

Fig-4: Showing increased bone density and osteolysis of terminal phalanges of index fingers (arrows)

\section{Discussion:}

Although our case had various features like small stature, beaked nose, hypoplasia of mid face, persistent fontanelles, blue sclera, proptosis, patent cranial sutures similar to that of other case reports but had no history of repeated chest infections, sleep apnea, kyphosis, and scoliosis. ${ }^{1-3}$ Our patient is a product of consanguineous marriage which supports the autosomal recessive trait of this disorder. Pyknodysostosis, by ultra structural studies have shown that the osteoclasts function normally in demineralizing bone but do not adequately degrade the organic matrix. ${ }^{6}$ In these patients, the serum and urine levels of NTX and CTX markers that detect $\mathrm{N}$ and $\mathrm{C}$ termini in telopeptide cross-links in collagen type I are low, showing defective degradation of 
collagen type I which constitutes $95 \%$ of the bone matrix. ${ }^{7}$ Till date 14 mutations have been identified in the CTSK gene, 12 being missense/nonsense, 1 splicing and 1 small deletion. ${ }^{7-9}$

However, our patient revealed features of bilateral otosclerosis which is rare at this age and needs further studies about this association so that early treatment modalities are used to decrease the morbidity in the already debilitated child.

\section{Conflict of interest: None}

\section{Referrences}

1. $\quad$ Maroteaux P, Lamy M. La Pycnodystose. Presse Med 1962; 70: 999-1002. [French]

2. Fleming KW, Barest G, Sakai O. Dental and facial bone abnormalities in pyknodysostosis: CT findings. AJNR Am J Neuroradiol 2007; 28: 132-134.

3. Schmitz JP, Gassmann CJ, Bauer AM, Smith BR. Mandibular reconstruction in a patient with pyknodysostosis. J Oral Maxillofac Surg 1996; 54:513-517.

4. Glass RB, Fernbach SK, Norton KI, Choi PS, Naidich TP. The infant skull: a vault of information.Radiographics 2004; 24: 507-522.
5. Singh AR, Kaur A, Anand NK, Singh JR. Pyknodysostosis: visceral manifestations and simian crease. Indian J Pediatr 2004; 71: 453-455.

6. Edelson JG, Obad S, Geiger R, On A, Artul HJ. Pyknodysostosis: Orthopedic Aspects with Description of 14 New Cases. Clin Orthop 1992; 280: 263-276.

7. Gelb BD, Spencer E, Obad S, Edelson JG, Faure S, Weissenbach, Desnick RJ. Pycnodysostosis: Refi ned Linkage and Radiation Hybrid Analyses Reduce the Critical Region to 2 cM at 1q21 and Map Two Candidate Genes. Hum Genet 1996; 98: 141-144.

8. Nishi Y, Atley L, Eyre DE, Edelson JG, Superti-Furga A, Yasuda $\mathrm{T}$ et al. Determination of Bone Markers in Pycnodysostosis: Effects of CathepsinK Defi ciency on Bone Matrix Degradation. J Bone Miner Res 1999; 14: 19021908.

9. Stenson PD, Ball EV, Mort M, Phillips AD, Shiel JA, Thomas NS et al. Human Gene Mutation Database (HGMD): 2003 update. Hum Mutat 2003; 21: 577-581. 